\title{
Expression of p53 and its mechanism in prostate cancer
}

\author{
JIUKAI WAN ${ }^{*}$, JUN ZHANG $^{*}$ and JUNQIANG ZHANG \\ Department of Urology, Zhengzhou Central Hospital Affiliated to Zhengzhou University, \\ Zhengzhou, Henan 450007, P.R. China
}

Received September 14, 2016; Accepted April 6, 2018

DOI: $10.3892 / \mathrm{ol} .2018 .8680$

\begin{abstract}
The present study aimed to investigate the expression of tumor protein p53 (p53), and its mechanism of function, in prostate cancer (PC). Small interfering RNA (siRNA) was used to interfere with p53 expression in the PC cell line, DU145. Cell viability and p53 expression were analyzed using cell counting kit-8 (CCK-8) and western blotting. The effects of p53 expression on the proliferation, migration and adhesion abilities of PC cells were analyzed using Cell Counting kit-8, Transwell and adhesion assays. Changes in cell proliferation, migration and adhesion ability were observed following treatment with extracellular signal-regulated kinase (ERK) inhibitor, PD184352, and janus kinase (JNK) inhibitor, SP60012. The expression level of p53 declined $24 \mathrm{~h}$ after siRNA transfection $(\mathrm{P}<0.05)$. Furthermore, JNK and ERK, downstream proteins of the focal adhesion kinase (FAK)-Src proto-oncogene, non-receptor tyrosine kinase ( $\mathrm{Src}$ ) signaling pathway, were activated. These effects were associated with reduced proliferation, migration and adhesion abilities of PC cells compared with untransfected control cells $(\mathrm{P}<0.05)$. PD184352 and SP600125 treatments also resulted in reduced proliferation, migration and adhesion abilities of PC cells $(\mathrm{P}<0.05)$. In conclusion, $\mathrm{PC}$ cells exhibited low p53 expression, and the proliferation, migration and adhesion abilities of PC cells were promoted by inhibiting the activation of JNK and ERK. Together, these results suggest that p53 has potential as a therapeutic target in PC.
\end{abstract}

\section{Introduction}

Among the most common types of cancer in males, prostate cancer (PC) is the second leading cause of cancer-associated mortality in the USA in 2011 (1). Currently, the first line of treatment for prostate cancer is surgery, however, it is not so ideal

Correspondence to: Professor Junqiang Zhang, Department of Urology, Zhengzhou Central Hospital Affiliated to Zhengzhou University, 195 Tongbai Road, Zhengzhou, Henan 450007, P.R. China

E-mail: junqiangzhangen@163.com

*Contributed equally

Key words: prostate cancer, proliferation, invasion following the operation. Gene-targeted therapy has provided a new perspective on cancer research, and the potential of tumor protein p53 (p53) in cancer treatment has become an increasingly prominent research theme (2-4). It has been well established that p53 is a tumor suppressor gene and that p53 mutations occur in 50\% tumor cells (5). Upon DNA-damage by radiation or other factors, $\mathrm{p} 53$ activates $\mathrm{p} 21$, which functions in DNA repair (6). At the S-stage of the cell cycle, damaged DNA cannot be repaired and p53 regulates cell apoptosis $(7,8)$. Previous studies have demonstrated that the focal adhesion kinase (FAK)/Src proto-oncogene, non-receptor tyrosine kinase (Src) pathway serves an important role in cell proliferation, differentiation, migration and survival, and is closely associated with the development, metastasis and prognosis of various types of cancer $(9,10)$. However, it remains unknown how p53 functions in the proliferation of PC cells, and whether the FAK/Src pathway is activated in the process. Therefore, the expression of p53 in PC cells its mechanism in the occurrence and development of PC was analyzed in the present study.

\section{Materials and methods}

Cell culture. RWPE-1 normal prostate cell line and the PC cell line, DU145, were purchased from Shanghai Institutes for Biological Sciences, Chinese Academy of Sciences (Shanghai, China). The cells were cultured in Dulbecco's modified Eagle's medium (DMEM; Hyclone; GE Healthcare Life Sciences, Logan, UT, USA) supplemented with $10 \%$ fetal calf serum (FBS; Zhejiang Tianhang Biotechnology Co., Ltd., Zhejiang, China), $100 \mathrm{U} / \mathrm{ml}$ penicillin (Beyotime Institute of Biotechnology, Shanghai, China) and $100 \mu \mathrm{g} / \mathrm{ml}$ streptomycin (Beyotime Institute of Biotechnology), at $37^{\circ} \mathrm{C}$ in $5 \% \mathrm{CO}_{2}$. The cells were passaged every 3-5 days.

Cell transfection. P53 small interfering RNA was designed and synthesized by GeneChem Inc. (Daejeon, Korea; Gene ID: GCD950481; sequence, 5'-GCAUGA ACCGGAGGC CCAU-3') and the control siRNA (cat no. D6145) was purchased from Takara Biotechnology Co., Ltd. (Dalian, China). The DU145 cells ( $1 \times 10^{6}$ cells) were seeded into a 6-well plate $24 \mathrm{~h}$ prior to transfection in the logarithmic growth period, and the DMEM culture medium (Hyclone; GE Healthcare Life Sciences) was discarded and replaced $2 \mathrm{~h}$ prior to transfection. The cells were then transfected with $5 \mu \mathrm{l}$ siRNA and $5 \mu$ l Lipofectamine ${ }^{\circledR} 2000$ (Thermo Fisher Scientific, Inc., Waltham, MA, USA). In the control group, DU145 cells were 
transfected with control siRNA under the same experimental conditions. A total of $4 \mathrm{~h}$ later, the medium was replaced and subsequent experiments were performed. PD184352 (25 $\mu \mathrm{mol} / \mathrm{l})$ and SP600125 $(25 \mu \mathrm{mol} / \mathrm{l})$ were purchased from Meiyan Biological Technology Co., Ltd. (Shanghai, China) and applied 24, 48 and $72 \mathrm{~h}$ post-transfection.

Western blotting. The cells were washed twice with PBS and $100 \mu 12 x$ Laemmli sample buffer (Kemin Biological Technology Co., Ltd., Shanghai, China) was added to lyse the cells. The samples were centrifuged for $30 \mathrm{~min}$ at $1,800 \mathrm{x} \mathrm{g}$ and $4^{\circ} \mathrm{C}$, and the supernatants were collected. Protein concentration was determined using a BCA bicinchoninic acid assay (Beyotime Institute of Biotechnology), according to the manufacturer's protocol. The absorbance was measured at $450 \mathrm{~nm}$ using a Benchmark microplate reader (Bio-Rad, Hercules, CA, USA) to determine protein concentration. The protein $(40 \mu \mathrm{g})$ was mixed with SDS loading buffer (Beyotime Institute of Biotechnology) and heated at $97^{\circ} \mathrm{C}$ for $3 \mathrm{~min}$. Following protein separation by $12 \%$ SDS-PAGE, the proteins ( $20 \mu \mathrm{g}$ per lane) were transferred into polyvinylidene fluoride membranes. The membranes were blocked in skimmed milk at room temperature for $2 \mathrm{~h}$, prior to being washed thrice with TBS containing $0.3 \%$ Tween (TBST). The membranes were incubated with mouse anti-human p53 primary antibody (cat no. MS-186-B; dilution, 1:500; Gibco; Thermo Fisher Scientific, Inc.), FAK antibody (cat no. ab40794; dilution, 1:500; Abcam, Cambridge, UK), Phospho (P)-FAK (Tyr925) polyclonal antibody (cat no. PA5-17733; dilution, 1:400; Thermo Fisher Scientific, Inc.), P-FAK (Tyr577) polyclonal antibody (cat no. PA5-37706; dilution, 1:500; Thermo Fisher Scientific, Inc.), P-FAK (Tyr397) polyclonal antibody (cat no. 44-624G; dilution, 1:500; Thermo Fisher Scientific, Inc.), extracellular signal-regulated kinase (ERK; cat no. ab17942; dilution, 1:400; Abcam), phosphorylated (p)-ERK (cat no. sc-7383; dilution, 1:400; Santa Cruz Biotechnology, Inc., Dallas, TX, USA) and $\beta$-actin (cat no. BM0627; dilution, 1:2,000; Wuhan Boster Biological Technology, Ltd., Wuhan, China) overnight at $4^{\circ} \mathrm{C}$. Subsequent to another 3 washes in TBST, a horseradish peroxidase-conjugated goat anti-mouse secondary antibody (cat no. BA1050; dilution, 1:10,000; Wuhan Boster Biological Technology, Ltd.) was incubated with the membranes at room temperature for $2 \mathrm{~h}$. Following 3 more washes in TBST, the protein bands were visualized using an enhanced chemiluminescence kit (Weipu Jishu, Shanghai, China; http://www. weipujishu.com/), according to the manufacturer's protocol. Results were analyzed using Image $\mathbf{J}$ software (version 1.38 ; National Institutes of Health, Bethesda, MD, USA) and the relative expression of target protein was calculated.

Cell counting kit-8 (CCK-8) assay. The cell concentration was adjusted to $1 \times 10^{5}$ cells $/ \mathrm{ml}$. A total of $100 \mu \mathrm{l}$ cell suspension was added per well in a 96-well plate and incubated at $37^{\circ} \mathrm{C}$ and in $5 \% \mathrm{CO}_{2}$ for $24 \mathrm{~h}$. Next, after $24 \mathrm{~h}, 100 \mu \mathrm{l} 10 \% \mathrm{CCK}-8$ reagent (Qianjian Green Sea Treasure Biological Technology Co., Ltd., Shanghai, China) was added to each well. After $2 \mathrm{~h}$, $10 \mu 10.1 \mathrm{M} \mathrm{HCl}$ was added to each well and the absorbance values were read immediately at $450 \mathrm{~nm}$.

Invasion assay. A total of $48 \mathrm{~h}$ after transfection, the DU145 cells $\left(1 \times 10^{6}\right.$ cells) cultured in DMEM (Hyclone; GE Healthcare

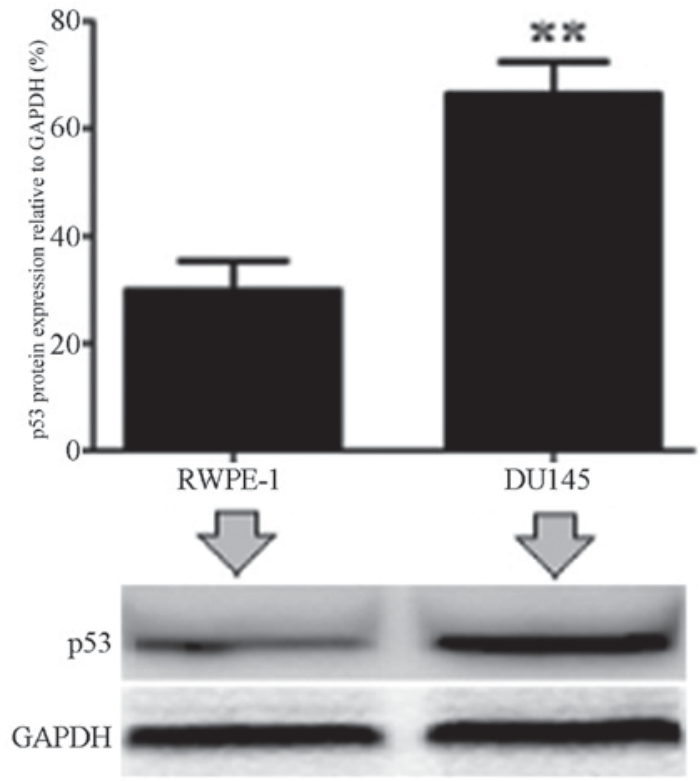

Figure 1. Protein expression level of p53 in normal cells and prostate cancer cells, analyzed by western blotting. ${ }^{* *} \mathrm{P}<0.01$ vs. RWPE- 1 cells. P53, tumor protein $\mathrm{p} 53$.

Life Sciences) were plated into the upper chamber ( $1 \times 10^{5}$ cells) of Transwell plates (Mingyangkehua Biological Technology, Co., Ltd, Beijing, China) coated with Matrigel, and $200 \mu \mathrm{l}$ DMEM medium containing $10 \%$ fetal bovine serum was added into the lower chambers and cultured for $24 \mathrm{~h}$. Hoechst $33258(5 \mu \mathrm{g} / \mathrm{ml}$; Shanghai Yanhui Biotechnology Co., Ltd., Shanghai, China) was incubated at room temperature with the cells for $2 \mathrm{~min}$. Using an inverted light microscope (magnification, x40; TS100; Nikon, Tokyo, Japan), the cells penetrating the membrane in 10 randomly selected fields of view were counted. The following formula was used to calculate the rate of migration inhibition: rate of migration inhibition $=$ (number migrated cells in the control group-number migrated cells in the experimental group)/number migrated cells in the control group x100.

Wound-healing assay. A total of $72 \mathrm{~h}$ after transfection, the DU145 cells cultured in DMEM (Hyclone; GE Healthcare Life Sciences) were plated in a 6 -well plate at $1 \times 10^{5}$ cells $/ \mathrm{ml}$. When confluence reached $100 \%$, a $10-\mu 1$ pipette tip was used to wound the cell layer. The plate was washed 3 times with PBS to remove the cell debris prior to adding fresh medium for $48 \mathrm{~h}$. Using an inverted light microscope (magnification, $\mathrm{x} 40$; TS100; Nikon, Tokyo, Japan), the cells were photographed at 0,24 and $48 \mathrm{~h}$.

Cell adhesion assay. Transfected cells were placed in a 96-well plate and incubated with blocking buffer $(0.5 \%$ bovine serum albumin, PBS pH 7.4 and $0.05 \%$ Tween 20; Biogot Technology Co., Ltd., Nanjing, China) at $37^{\circ} \mathrm{C}$ in $5 \% \mathrm{CO}_{2}$. The cells were washed twice in PBS prior to fixation in $4 \%$ paraformaldehyde at $37^{\circ} \mathrm{C}$ for $30 \mathrm{~min}$ and a $10 \mathrm{~min}$ incubation at $37^{\circ} \mathrm{C}$ with $0.1 \%$ crystal violet. The cells were then treated with $0.05 \%$ Tween-20 for $30 \mathrm{~min}$ at room temperature, and the absorbance values were read at $595 \mathrm{~nm}$.

Statistical analysis. All data are expressed as the mean \pm standard deviation and were analyzed using SPSS 19.0 
A

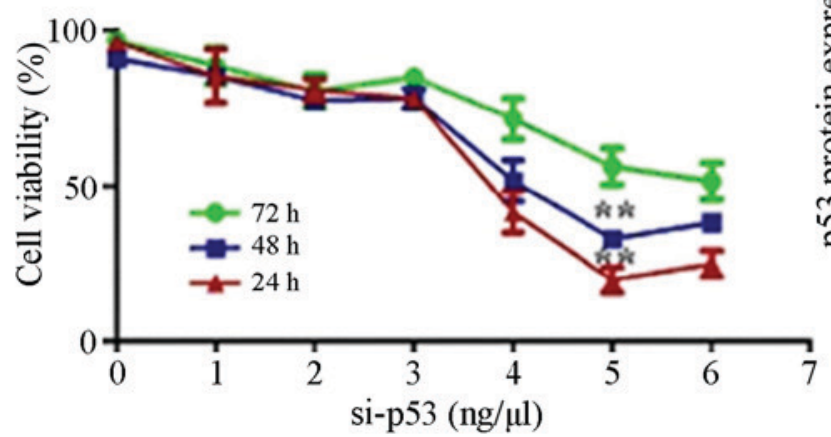

$\mathrm{B}$

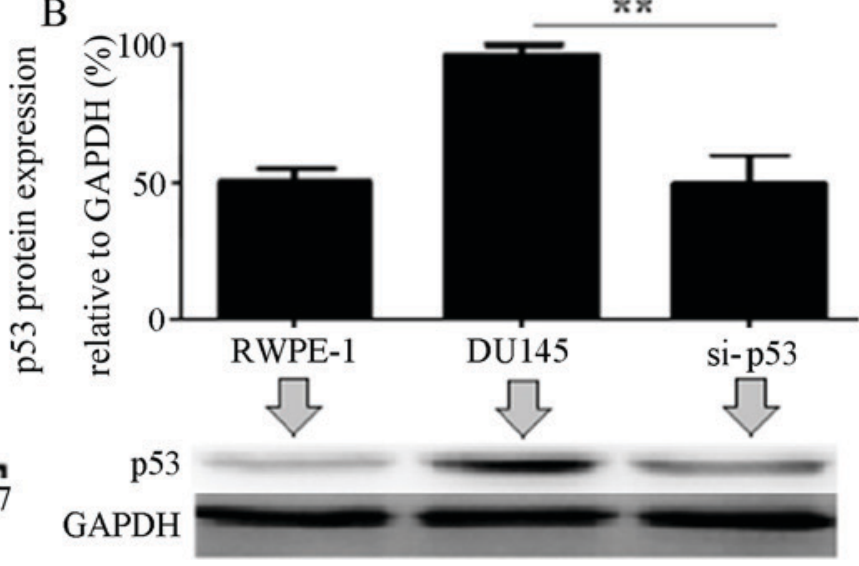

Figure 2. The effect of si-p53 on cell viability and protein expression level of p53, analyzed using Cell Counting kit- 8 and western blotting. (A) The viability of DU145 cells after 24-, 48- and 72-h treatments with $0,1,2,3,4,5$ or $6 \mathrm{ng} / \mu \mathrm{l}$ si-p53. ${ }^{* *} \mathrm{P}<0.01 \mathrm{vs.} 72 \mathrm{~h}$. (B) Expression of p53 in DU145 cells after $24 \mathrm{~h}$ with $5 \mathrm{ng} / \mu 1$ si-p53. ${ }^{* *} \mathrm{P}<0.01$ vs. si-p53. si-p53, small interfering RNA targeting p53; p53, tumor protein p53.
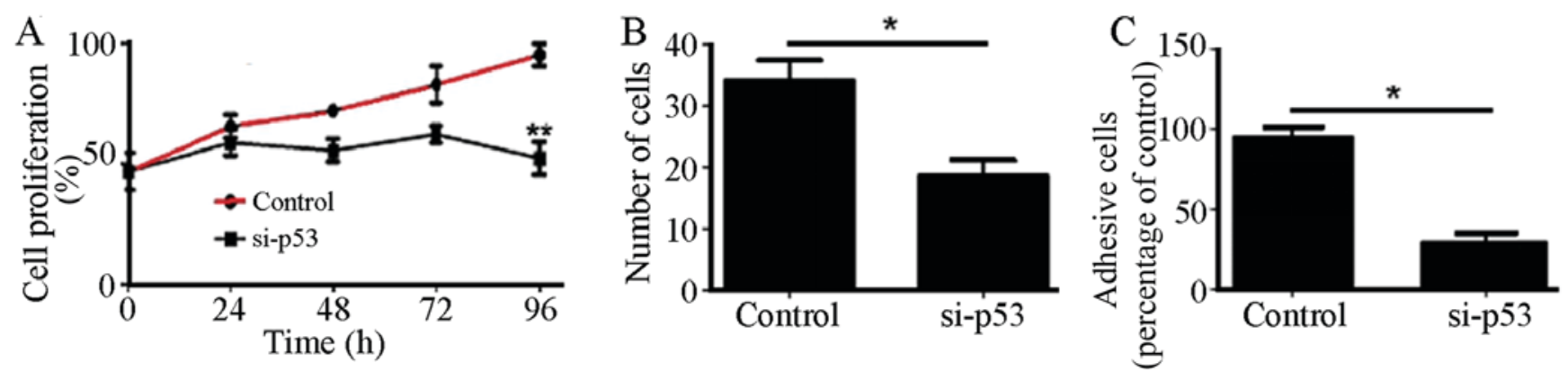

Figure 3. Effects of si-p53 interference on the proliferation, invasion and adhesion abilities of DU145 cells. (A) Effect of si-p53 transfection on the percentage of proliferating DU145 cells. (B) Effect of si-p53 transfection on the number of DU145 cells which invaded through the Transwell membrane. (C) Effect of si-p53 transfection on the adhesion ability of DU145 cells. "P $<0.01$ vs. control; ${ }^{* *} \mathrm{P}<0.05$ vs control si-p53, small interfering RNA targeting p53; p53, tumor protein p53.

software (IBM Corp., Armonk, NY, USA). Multiple-group comparisons were performed using one-way analysis of variance and the Least Significant Difference test. Comparisons between 2 groups were performed using the unpaired Student's t-test. $\mathrm{P}<0.05$ was considered to indicate a statistically significant difference.

\section{Results}

Protein expression level of $p 53$ in prostate cancer cells. The expression of p53 was analyzed in normal RWPE-1 cells and PC DU14 cells by western blotting. It was demonstrated that the p53 protein expression level was significantly increased in DU145 cells compared with normal control cells $(\mathrm{P}<0.01$; Fig. 1).

p53 expression is suppressed following interference using si-p53 in DU145 cells. To assess the efficiency of si-p53 transfection, the cell viability and protein expression level of p53 were analyzed 24,48 and $72 \mathrm{~h}$ after transfection with $0,1,2$, $3,4,5$ and $6 \mu \mathrm{l}$ si-p53. It was revealed that $24 \mathrm{~h}$ after treatment with $5 \mu 1$ si-p53, the viability of DU145 cells declined remarkably compared with untransfected cells $(\mathrm{P}<0.01)$. The result was quite similar following treatment with $6 \mu \mathrm{l}$ si-p53 (P>0.05; Fig. 2A). Western blotting revealed that $24 \mathrm{~h}$ after a $5-\mu 1$ si-p5 treatment, the expression level of p53 was significantly reduced compared with untransfected cells ( $\mathrm{P}<0.01$; Fig. 2B).

Effect of si-p53 interference on the proliferation, invasion and adhesion abilities of DU145 cells. The proliferation, migration and adhesion abilities of cells transfected with si-p53 were significantly reduced compared with untransfected cells $(\mathrm{P}<0.01$; Fig. 3).

Effect of si-p53 interference on the FAK-Src signaling pathway. To study the mechanism behind the effect of p53 on the proliferation, invasion and adhesion abilities of PC cells, the effect of si-p53 treatment on FAK/Src/mitogen-activated protein kinase (MAPK) pathway, which is closely associated with cell adhesion and motility, was investigated. The results revealed that si-p53 treatment resulted in a significant increase in the expression levels of FAK, p-FAK, Src, p- ERK and p-janus kinase $(\mathrm{JNK})$ compared with untreated cells $(\mathrm{P}<0.05$; Fig. 4).

PD184352 and SP600125 treatment alters the proliferation, migration and adhesion abilities of DU145 cells. Preliminary experiments indicated that 10 ìM PD184352 and SP600125 inhibitors reduced the proliferation, invasion and adhesion abilities of PC cells compared with untreated cells (Fig. 5). 


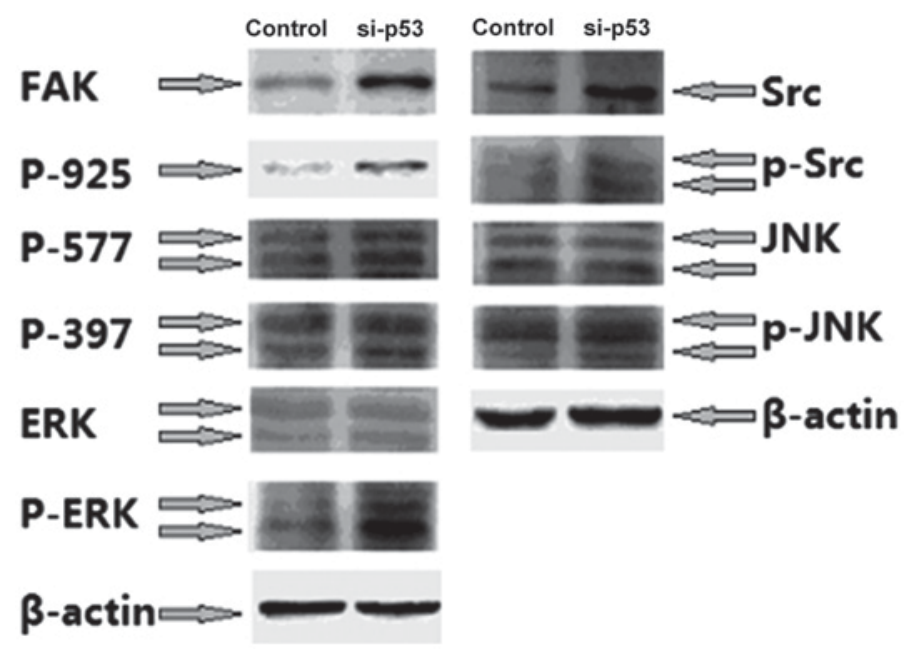

Figure 4. Western blotting was used to demonstrate that FAK-Src signaling is activated by si-p53. FAK, focal adhesion kinase; Src, Src proto-oncogene, non-receptor tyrosine kinase; si-p53, small interfering RNA targeting p53; p53, tumor protein p53; ERK, extracellular-regulated kinase; p-, phosphorylated; JNK, janus kinase; P-925, Phospho-FAK Tyr925; P-577, Phospho-FAK Tyr577; P-397, Phospho-FAK Tyr397.
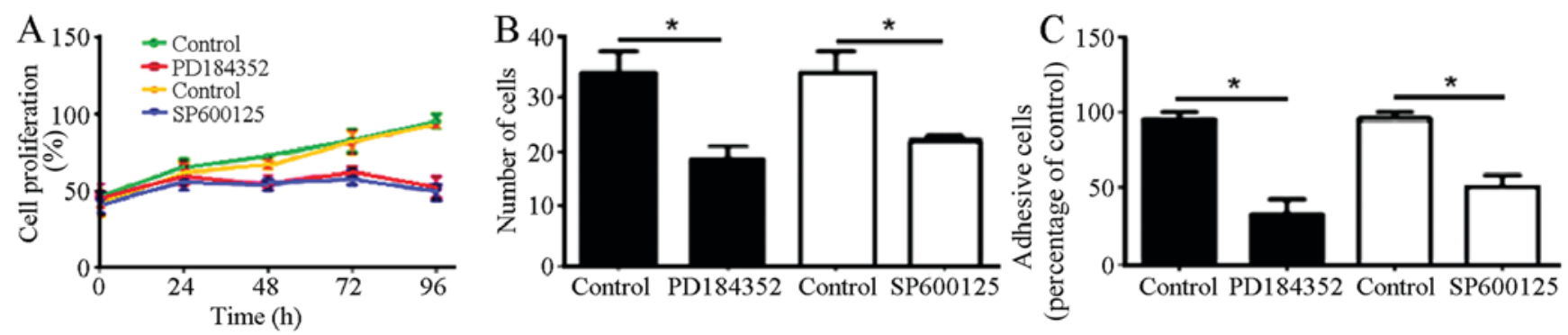

Figure 5. Effects of PD184352 and SP600125 on the proliferation, invasion and adhesion abilities of DU145 cells. (A) Effects of PD184352 and SP600125 on the percentage of proliferating DU145 cells. (B) Effects of PD184352 and SP600125 on the number of DU145 cells which invaded through the Transwell membrane. (C) Effects of PD184352 and SP600125 on the adhesion ability of DU145 cells. "P<0.05 vs. control.

\section{Discussion}

In the past ten years, prostate cancer has been revealed to be the most common type of tumor among males globally (11). The main cause of prostate cancer is unknown, however, it has been associated with various factors, including heredity, environment and sex hormone levels (10). Although hormonotherapy has progressed, it effectiveness is limited due to hormone desensitization (12). Consequently, the discovery of novel therapeutic targets is urgently required.

As a negative regulator of cell growth, mutations in p53 result in dysregulation of the cell cycle, causing abnormal proliferation and malignant transformation (13). Research has demonstrated that abnormal expression of p53 in tumor tissue is closely associated with tumor lymph node metastasis, clinical stage and clinicopathology (14-16). However, it remains unclear how abnormal expression of p53 affects the malignant proliferation, metastasis and differentiation of prostate cancer cells.

The present study demonstrated that p53 interference may inhibit the proliferation, migration, adhesion and migratory abilities of DU145 cells. The specific mechanism of these effects of p53 was also investigated in the present study. FAK is a major focal ohesion that serves an important role in cell survival and migration (17). Following external activation of the FAK pathway, auto-phosphorylation of Tyr397 occurs, followed by the formation of FAK/Src composite, causing the phosphorylation of Tyr925 and the activation of Ras and MAPK proteins (18). The results of the present study indicate that interference with $\mathrm{p} 53$ expression causes FAK/Src pathway activation and increased JNK and ERK phosphorylation levels. Inhibition of ERK and JNK activity by PD184352 and SP600125 decreased the proliferation, migration and adhesion abilities of DU145 cells, implying that p53 controls these PC-cell functions through the phosphorylation JNK/ERK.

To conclude, high protein expression levels of p53 in PC cells was closely associated with cell proliferation, migration and adhesion abilities, in which the FAK-Src-MAPK pathway serves a crucial role. p53 may be an effective anti-cancer target for suppression of the malignant proliferation of PC cells, and for prostate cancer gene therapy.

\section{Acknowledgements}

Not applicable.

\section{Funding}

No funding was received. 


\section{Availability of data and materials}

All data generated or analysed during this study are included in this published article.

\section{Authors' contributions}

JKW and JQZ conceived the study design and drafted the manuscript. JZ participated in the study design and coordination. All authors revised and approved the final manuscript.

\section{Ethics approval and consent to participate}

The present study was approved by the Ethics Committee of Zhengzhou Central Hospital Affiliated to Zhengzhou University (Zhengzhou, China). Written informed consent was gained from all participants.

\section{Consent for publication}

All subjects participating in the present study have provided consent for the publication of this data.

\section{Competing interests}

The authors declare that they have no competing interests.

\section{References}

1. Jemal A, Bray F, Center MM, Ferlay J, Ward E and Forman D: Global cancer statistics. CA Cancer J Clin 61: 69-90, 2011.

2. Jiang T, Zhou C, Gu J, Liu Y, Zhao L, Li W, Wang G, Li Y and Cai L: Enhanced therapeutic effect of cisplatin on the prostate cancer in tumor-bearing mice by transfecting the attenuated Salmonella carrying a plasmid co-expressing p53 gene and mdm2 siRNA. Cancer Lett 337: 133-142, 2013.

3. Nande R, Greco A, Gossman MS, Lopez JP, Claudio L, Salvatore M, Brunetti A, Denvir J, Howard CM and Claudio PP: Microbubble-assisted p53, RB, and p130 gene transfer in combination with radiation therapy in prostate cancer. Curr Gene Ther 13: 163-174, 2013.

4. Wang Y, Zhang YX, Kong CZ, Zhang Z and Zhu YY: Loss of P53 facilitates invasion and metastasis of prostate cancer cells. Mol Cell Biochem 384: 121-127, 2013.

5. Sivoňová MK, Vilèková M, Kliment J, Mahmood S, Jureèeková J, Dušenková S, Waczulíková I, Slezák P and Dobrota D: Association of $\mathrm{p} 53$ and $\mathrm{p} 21$ polymorphisms with prostate cancer. Biomed Rep 3: 707-714, 2015.
6. Gu J, Wang B, Liu Y, Zhong L, Tang Y, Guo H, Jiang T, Wang L, Li Y and Cai L: Murine double minute 2 siRNA and wild-type p53 gene therapy interact positively with zinc on prostate tumours in vitro and in vivo. Eur J Cancer 50: 1184-1194, 2014.

7. Xie Q, Lu YY and Yi HF: Expression and clinical significance of Caspase-3 and P53 in gastric cancer. Chin J Gastroenterol Hepatol 23: 1287-1289, 2014.

8. Ha US, Bae WJ, Kim SJ, Yoon BI, Hong SH, Lee JY, Hwang TK, Hwang SY, Wang Z and Kim SW: Anthocyanin induces apoptosis of DU-145 cells in vitro and inhibits xenograft growth of prostate cancer. Yonsei Med J 56: 16-23, 2015.

9. Teh BS and Ishiyama H: Hypofractionated radiotherapy for prostate cancer. Lancet Oncol 13: 5-6, 2012.

10. Henríquez-Hernández LA, Valenciano A, Foro-Arnalot P, Álvarez-Cubero MJ, Cozar JM, Suárez-Novo JF, Castells-Esteve M, Fernández-Gonzalo P, De-Paula-Carranza B, Ferrer $\mathrm{M}$, et al: Genetic variations in genes involved in testosterone metabolism are associated with prostate cancer progression: A Spanish multicenter study. Urol Oncol 33: 331. e1-e7, 2015

11. Thomsen FB, Folkvaljon Y, Garmo H, Robinson D, Loeb S, Ingvar C, Lambe M and Stattin P: Risk of malignant melanoma in men with prostate cancer: Nationwide, population-based cohort study. Int J Cancer 138: 2154-2160, 2016.

12. Alva A and Hussain M: Optimal pharmacotherapeutic management of hormone-sensitive metastatic prostate cancer. Drugs 73: 1517-1524, 2013.

13. Meek DW: Regulation of the $\mathrm{p} 53$ response and its relationship to cancer. Biochem J 469: 325-346, 2015.

14. Singh RD, Patel KR and Patel PS: p53 mutation spectrum and its role in prognosis of oral cancer patients: A study from Gujarat, West India. Mutat Res 783: 15-26, 2016.

15. Zhang G, Li Z, Lin XM, Zhang JH, Cui Y and Zhao X: Expression and significance of PTEN, S100A4 and p53 protein in breast invasive ductal carcinoma. Guangdong Med J 35: 3510-3512, 2014.

16. Cai $\mathrm{S}$ and Han K: Research on expression and importance of p53, p16 and VEGF-C in cervical cancer. J Gynecol Obstet Biol Reprod (Paris) 44: 639-645, 2015.

17. Thakur R, Trivedi R, Rastogi N, Singh M and Mishra DP: Inhibition of STAT3, FAK and Src mediated signaling reduces cancer stem cell load, tumorigenic potential and metastasis in breast cancer. Sci Rep 5: 10194, 2015.

18. Zhang H, Zhang SH, He HW, Zhang CX, Yu DK and Shao RG: Downregulation of G3BPs inhibits the growth, migration and invasion of human lung carcinoma H1299 cells by suppressing the Src/FAK-associated signaling pathway. Cancer Gene Ther 20: 622-629, 2013.

This work is licensed under a Creative Commons Attribution-NonCommercial-NoDerivatives 4.0 International (CC BY-NC-ND 4.0) License. 